\title{
A Frankenstein-inspired Engineering Design Project
}

\section{Dr. James "Jamie" Canino, Trine University}

Jamie Canino is currently an associate professor at Trine University where he focuses on undergraduate education research. He teaches in the thermal-fluids and aerospace engineering fields and can be reached at caninoj@ trine.edu.

\section{Dr. Kendall B. Teichert, Trine University}

Dr. Teichert received his B.S. and M.S. in Mechanical Engineering from Brigham Young University. His Masters research studied behavior of microelectromechanical sensors/actuators. He worked for a small engineering firm in Salt Lake City, Utah before returning to school. Dr. Teichert received his $\mathrm{PhD}$ from University of Michigan, where he focused on modeling of cyclic loading for batteries in a particular microrobotic application. Dr. Teichert is an assistant professor in Trine University's, Wade department of Mechanical and Aerospace Engineering, where he teaches dynamics, mechanics of machinery, as well as introductory first-year courses. 


\title{
A Frankenstein Inspired Engineering Design Project
}

\author{
Abstract \\ In 2018, people all over the world were reading Frankenstein in celebration of its $200^{\text {th }}$ \\ anniversary. There is no doubt that the ideas explored in Frankenstein are still timely and \\ important to today's engineers. However, Frankenstein is rarely discussed in technical classes. \\ This paper discusses a design project for first-year Mechanical Engineering students that asked \\ students to select and explore themes from Frankenstein as a guide for the design of an \\ autonomous robot. In essence, the students were required to develop a target customer that would \\ benefit from the theme they selected. The use of the novel to generate concepts for the robots \\ was supported by using a form of double column notes. This processes required the students to \\ select several quotes from the book as inspiration for concept generation. Students sketched the \\ robot ideas and explained the connection between the quote from the book and the concept. \\ The primary contribution of this work is the lessons learned through the process of \\ implementing this project. These lessons learned are illustrated using student work and an \\ analysis of a survey to determine students' experiences with the project. \\ Among the findings reported is the observation that many students developed merely a \\ superficial, or surface level, connection to the literature. However, other students were able to \\ delve deeper, presenting ideas such as social rejection. Telling results are presented from a \\ student survey about the experience indicated that only $11 \%$ of the students read the entire book \\ whereas $22 \%$ said they read $20 \%$ or less of the book, and only $15 \%$ of students reported enjoying \\ reading the book. Perhaps most encouraging, $67 \%$ of students reported that there are important \\ concepts in Frankenstein for today's engineers, and 63\% said it was moderately to highly
}


important to incorporate humanities into science and engineering. These findings suggest an acknowledgment of the importance of the humanities in STEM from the students, and provide valuable insight for future implementation.

\section{Introduction}

The first mechanical engineering class freshman take at Trine University incorporates a design project as part of the class. Cornerstone design projects have been used as part of freshman or sophomore engineering curriculum for decades[1] and faculty continue to publish papers on the development of their freshman design experiences today[2]. The current iterations of freshman design courses often revolve around ideas like social justice[3], Human-Centered Design[4], Sustainable design[5], or some other means of asking students to engage with design besides simply focusing on technical requirements $[6,7]$.

One of the author's own experiences with a freshman design project revolving around the design, build, and test of a scale model of a passive solar home, demonstrates why requiring student to engage beyond the technical requirements is so important in engineering design. After the first iteration of the design project it because obvious that students only addressed the technical requirements for the project without ever thinking about the fact people live in homes. Therefore, on a subsequent iteration of the passive solar home, professors in the Humanities Department were asked to serve as customers for the homes. Each group was required to interview their customer and present preliminary and final designs to them. This process yielded significantly better designs. Therefore, when one of the Humanities faculty asked if the Mechanical Engineering Department could participate in Frankenstein events in celebration of the $200^{\text {th }}$ anniversary of its publication, it seemed like a natural fit for the freshman design class. 
This is especially true since connecting humanities and engineering has been a topic of interest for some time. For example, engineering faculty have helped develop Humanities class specifically tailored to engineering students[8], and provided design projects for engineers in art, music, dance, and theatre[9]. The 2018 publication from The National Academies of Engineering and Sciences outlines 100's of collaborations between STEM and Humanities and Arts faculty[10]. The report states that researchers have found the integration of STEM and the humanities increases knowledge retention and can make learning more engaging. For a more complete analysis of the benefits of these efforts the interested reader is directed to the National Academies report.

This paper describes a design project given to first-year engineering students that allowed them to experiment with connecting engineering and the humanities. The project invited students to use Mary Shelley's classic novel Frankenstein as a platform to generate concepts for robots that would explore themes from the book. An overview of the project and requirements for the students, selected student work, findings from feedback survey, overall outcomes and experiences, and how this implementation of Humanities in engineering continues to develop is discussed.

\section{Design Project}

As noted, this design project was presented as a way to connect the humanities and engineering. The students were assigned to read or listen to the text of Frankenstein[13], and use that as a springboard for the creative process in designing a robot that explored a theme from the text. The students were provided possible prompts to respond to as part of their assignment. These prompts included developing a Frankenstein experience for Disney, reacting to 
Greenpeace's video on NewBees[11], exploring the Kinetic Art movement[12], or exploring a theme from Frankenstein.

To aid the students in the process of exploring a literary piece for design ideas, two main additions were added to the requirements for the project. The first was a structured way to interact with the book that allowed students to document passages that could be used for inspiration in the design process, to convert these to a visual representation of a concept, and to verbally portray the connection between the design and the passage. These "reflection" assignments were accomplished through a type of two column notes. The second was to provide a list of technical objectives for the robot. This allowed the students to have a familiar set of specific engineering requirement in addition to the thematic requirements.

\section{Reflection Assignments}

The novel is broken into three sections or volumes, with additional commentary provided by the editors of the MIT press version of Frankenstein[13]. The students were required to submit a reflection for each section as well as to choose one of the essays included at the end of the book. Samples of student work from the first three reflections are given. The first set of sample reflection (reflections 1-3) show surface, or superficial, connections with the text. These reflections take a phrase or event in the book, and directly incorporate that into the concept for the student's robot. The specific action or event is the only correlation with the text, and lacks any thematic connection. When all reflections are analyzed it is apparent most students were not able, or unwilling, to get past these superficial connections.

However, some students, as demonstrated by reflection examples 4-6, showed greater thematic connection to the text albeit, in varying degrees. Two example reflections were given to 
the students from the professors at the beginning of the project and some of the reflections shown seem to draw on those (e.g. having a robot that writes a message). The nature of the reflection samples are self-explanatory, so they are given below with only minor corrections.

\section{Reflection Sample 1}

Book Quote (Page 28): "I threw myself into the chaise that was to convey me away, and indulged in the most melancholy reflections. I, who had ever been surrounded by amiable companions, continually engaged in endeavoring to bestow mutual pleasure, I was now alone. In the university, whither I was going, I must form my own friends, and be my own protector."

Student Response: In this part of the book Dr. Frankenstein is moving away to attend university in a far-off place. He is going off all by himself to live on his own for the first time. He has no friends and must make all new acquaintances. They also talk some about reading once he got to university so that is why I drew it [the robot concept] carrying a book. I once had to move off to university, but I did not move alone. I had help from my friends and family and it made it very easy to move my stuff. Carrying all the things it would take to live on your own to a completely new place would be difficult. This led me to design a robot that could help move things, so you could carry other things. It can pick them up with the arm and then move them into the basket to be carried to their destination. This would be very useful for moving things into places where people would not fit. Also, it could be used to take my books to class, so I wouldn't have to carry them. The design for the basket was inspired by the Jawa sandcrawlers of Star Wars.

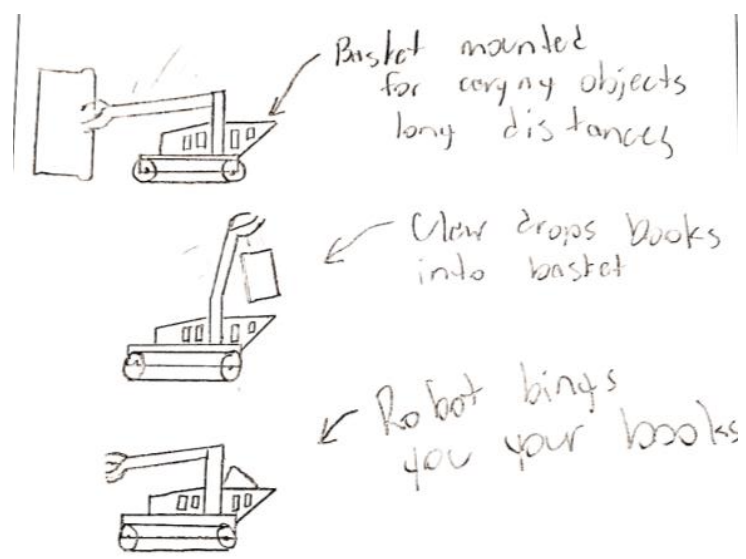

Figure 1 Sketch for reflection sample 1, moving help.

Reflection Sample 2 
Book Quote (Page 79): "As I said this, I suddenly beheld the figure of a man, at some distance, advancing towards me with superhuman speed."

Student Response: The reason I chose this quote was because I could imagine the power and speed inside my head. I thought about how impressive it would be to be able to see something move so quick and agile. I enjoy sports and this quote made me think of the competitive edge some athletes have with their speed. It is a way that athletes are judged upon. I would want my robot to possess the same ability to move quickly to where it seems as if it is floating. People and things that have great speed have always amazed me. I would want my robot to be the Usain Bolt of robots. I would want to make my robot aerodynamic and fast but also be able to move in all directions easily. I would make it so that all the speed would be controlled so it would not tip over.

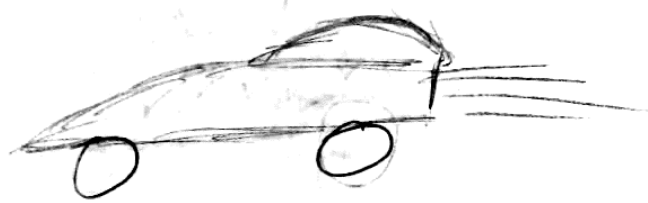

Figure 2 Sketch for reflection sample 2, fast robot.

\section{Reflection Sample 3}

Book Quote (Page 159): "As the period fixed for our marriage drew nearer, whether from cowardice or a prophetic feeling, I felt my heart sink within me. But I concealed my feelings by an appearance of hilarity, that brought smiles and joy to the countenance of my father, but hardly deceived the ever-watchful and nicer eye of Elizabeth."

Student Response: The marriage was a short scene in the book, but it grabbed my attention. As all the characters involved except Frankenstein are excited and feeling happy. This is because of the stress that his monster's life has given him. In preparation of the wedding Frankenstein carried a gun and dagger for protection from the monster. The marriage should bring him joy but he only becomes more worried for the lives of his family. The marriage is what got me thinking of [a] way to incorporate the robot in a wedding ceremony. The idea that jumped into my head is to have the robot act as a ring bearer and or flower girl. This would include the robot being able to travel down the aisle with the rings on it. With the claw it could then grab the rings and raise them up to until taken. With the flower girl robot, it would have a load of flowers and in a similar fashion it would grab the flower petals and then release them down the aisle. This would require coding for the robot to travel down [the] aisle with frequent stops to drop the flower petals. And for the ring bearer to travel and stop before the bride and groom. This would relate to the wedding in the book. 


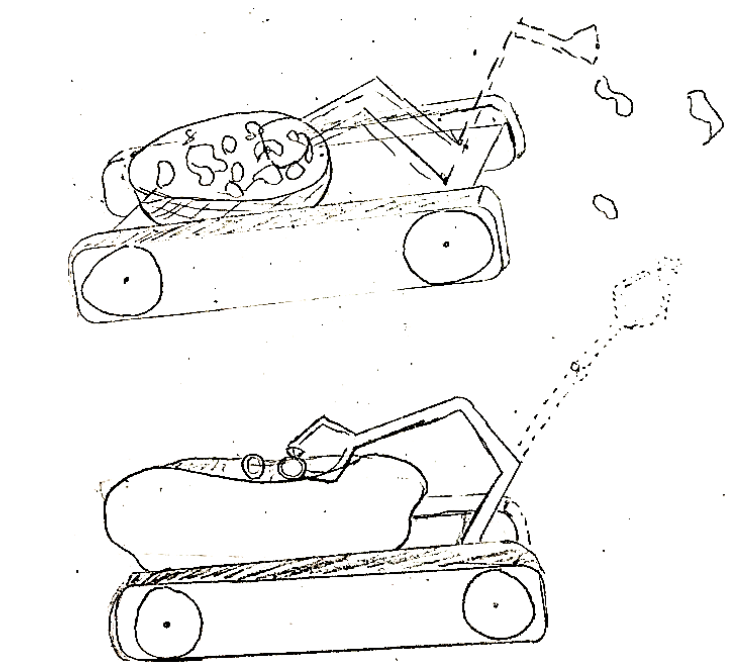

Figure 3 Sketch for reflection sample 3, wedding robot.

\section{Reflection Sample 4}

Book Quote (Page 120): "You must create a female for me, with whom I can live in the interchange of those sympathies necessary for my being."

Student Response: During the second Volume of Frankenstein, the monster has learned self-awareness and hone[d] all of his capabilities. The monster has learned how to speak, read, and write. It has also learned different emotions like love, hate, anguish, and loneliness. In the previous reflection, I wanted my robot to be able to listen, learn, and respond. I'm not able to make my robot feel emotions, but I want my robot to be able to ask for a companion.

Frankenstein's monster's main goal in the second volume was to talk about his terrible life, and then ask for a female. In reality, the monster just wants someone to love him and be his friend. The monster has lived a lonely life, and he doesn't want to feel lonely anymore. I want my robot to be able to identify that it is not a human, and therefore one of its own race. It will then come to me, its creator, and ask for a friend so that it won't be lonely anymore. The robot will then roll around the room scanning for another robot. My robot will then express to the other robot that they are friends and of the same species. It will then come back to me and thank me for "creating" a friend for it to live with. 


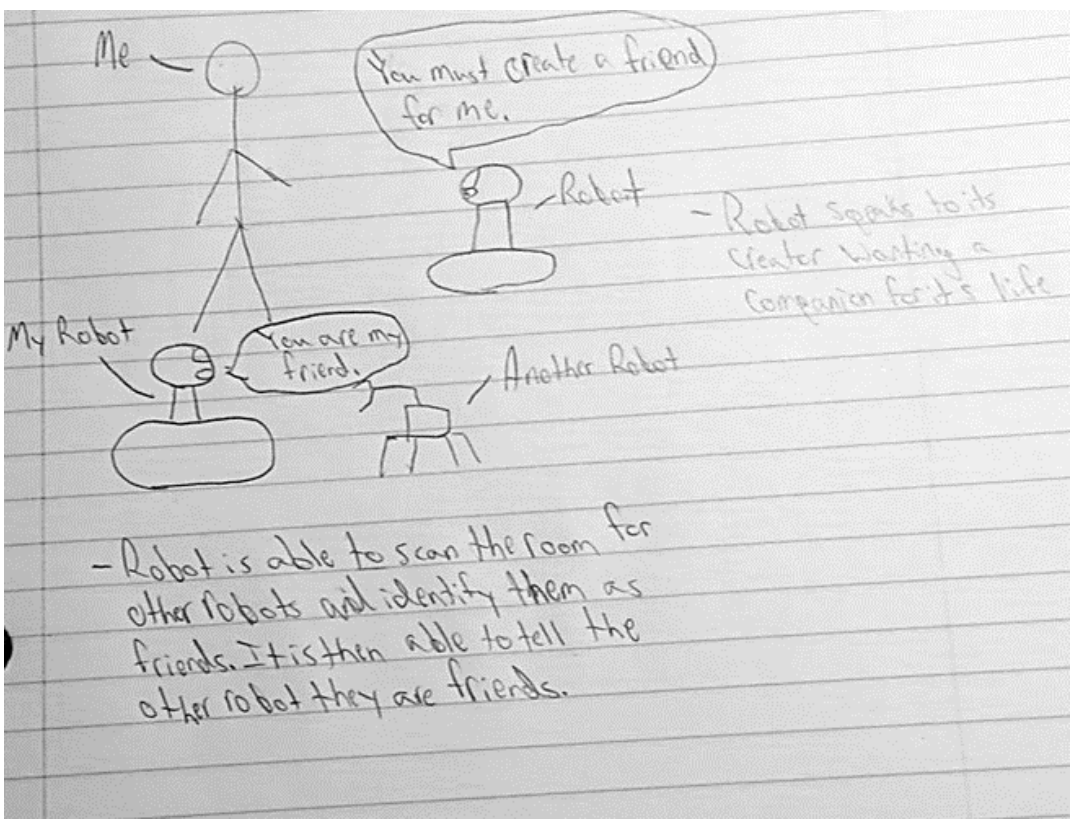

Figure 4 Sketch for reflection sample 4, friendship.

\section{Reflection Sample 5:}

Book Quote (Page 51): "Ever since the fatal night, the end of my labors, and the beginning of my misfortunes, I had conceived a violent antipathy even to the name of natural philosophy."

Student Response: My sketch is text that the robot would draw during the demonstration. The connection between the quote and the text drawn comes from the role ethics play in science. The quote comes as Victor has realized the consequences of animating his creation. Ethics are important when researching in science because there are things that should not be done. There has to be boundaries for research so that whatever is being researched is used for the right reasons. Atomic technology is a perfect example of a double edged sword. On one hand, atomic energy is clean, medicines using radioactive markers are extremely useful in research, and may be useful in making discoveries in astronomy. However, the original research had a much more violent use. By splitting an atom to create a nuclear chain reaction, scientists in the US were able to create the first nuclear bombs. This technology has so far led to 2 cities in Japan being leveled with millions of civilian deaths, radiation poisoning among survivors of those bombings, and is responsible for worldwide instability due to new nuclear nations. Without ethical considerations, many more discoveries may be turned into devices of havoc. Therefore, as we research new technologies we must ensure that they are used for responsible reasons. 


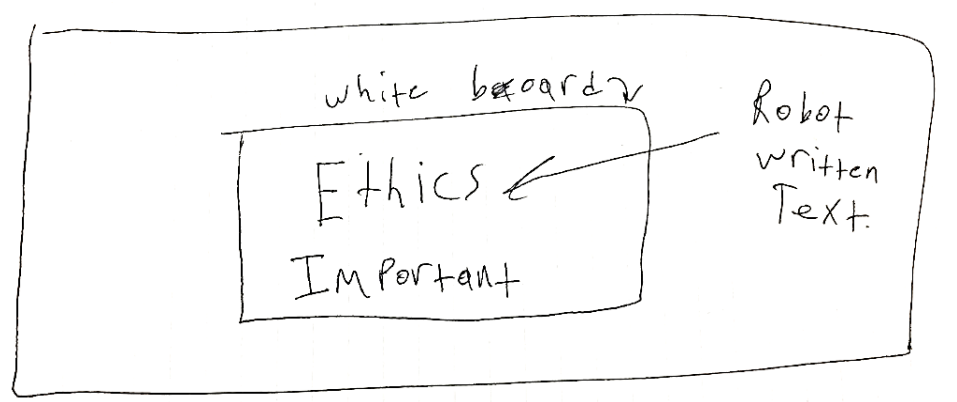

Figure 5 Sketch for reflection sample 5, ethics.

\section{Reflection Sample 6}

Book Quote (Page 158): "My dear Victor, do not speak thus. Heavy misfortunes have befallen us; but let us only cling closer to what remains, and transfer our love for those whom we have lost to those who yet live."

Student Response: This passage has inspired me to use the ultra-sonic sensors and the claw to pick up several separated objects and move them to a single area. Relating this to the passage, the objects that is being picked up by the robot, represent "love" that Alphonse Frankenstein mentioned. There would be a total number of objects being moved would be 3. Each one representing the death of Victor Frankenstein's loved ones. All three object presents each [sic] of William, Justine and Elizabeth. So in a sense our robot is relocating his love to the love[d] ones [he has] left, the end are [sic] I mentioned. The process is going to be a lot of tracing back code and making the robot find the objects in a timely manner. The gyroscope will be used quite a bit to allow the robot [to] turn precise angles. The gyro and the senor are the heart of the movement of the robot, but the claw is the only thing that will complete the objective I want.

\section{Project Technical Requirements}

Technical requirements for the robot were also given for the robot regarding function, fabrication, and design. The robots designed and created were able to meet the vast majority of these technical requirements. The technical requirements included the following:

1. The robot must be able to move forward, backward, and make a turn autonomously.

2. The robot must travel to a point at least 5 feet from the starting location.

3. The robot must be able to traverse a 10 degree incline.

4. In addition to locomotion, the robot must have one other mechanical motion capability (e.g. movement of an arm). 
5. The robot should have at least two types of sensing and must be able to appropriately respond to feedback from these sensors.

6. The robot must be able to operate for at least $1 \mathrm{~min}$ but no more than $3 \mathrm{~min}$.

7. The robot must remain fully functional after (and during) the demonstration.

8. The robot must demonstrate some type of physical interaction with its environment (besides simple locomotion).

9. At least $40 \%$ (by count) of the essential structural/mechanical components of the final robot need to be fabricated by the team.

10. You need to use one of the following three items in your design project: laser cutter, plasma cutter, or the 3D printers.

11. You must demonstrate design iteration. Therefore, you must test and improve your design at least twice before the demonstration (i.e. you need to have built 2 prototypes and your final robot).

\section{Final Robot Presentation/Report}

The final robots created by the groups showed a variety of different levels of connection with the book. Two examples of final robots as displayed on Trine University's event images page, are shown in Figure 6. These represent some of the superficial connections to the text that were seen. Including several robots that focused on plowing snow or other chores that the Creature does for the villagers. These merely captured an action or event of the book and not a real thematic connection.
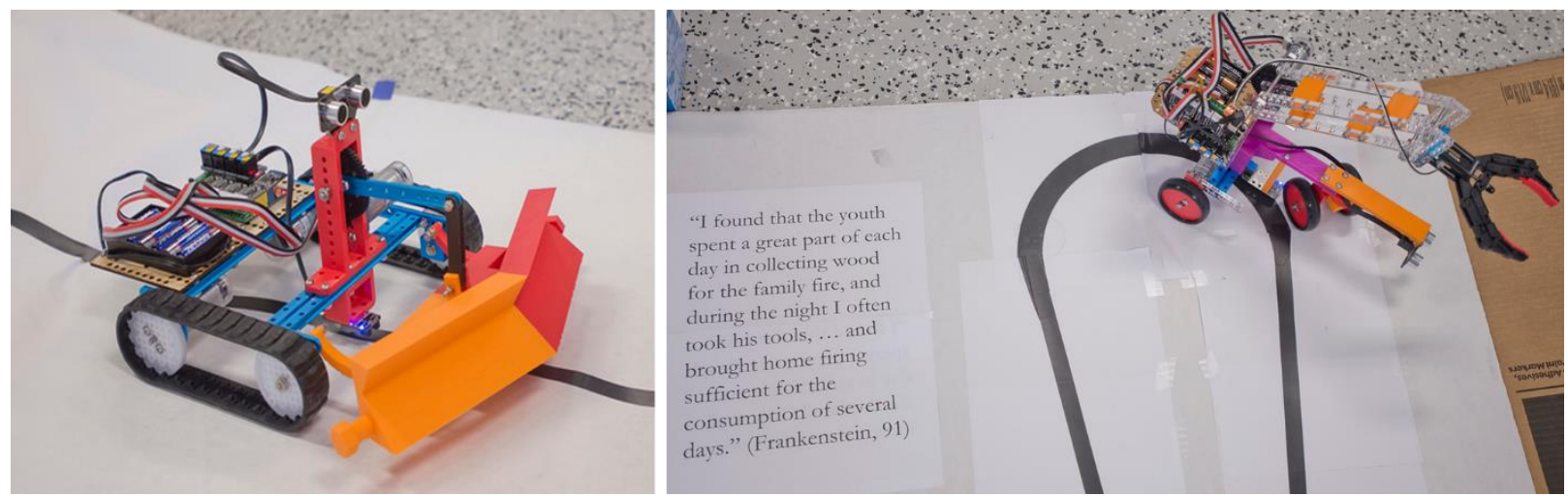

Figure 6. Examples of "Snow Plow" robot and a "helper" robot 
However, in the authors' opinion there were a few groups that engaged with the text more deeply, albeit, to varying degrees. The robot shown in Figure 7 explored the theme of social rejection.
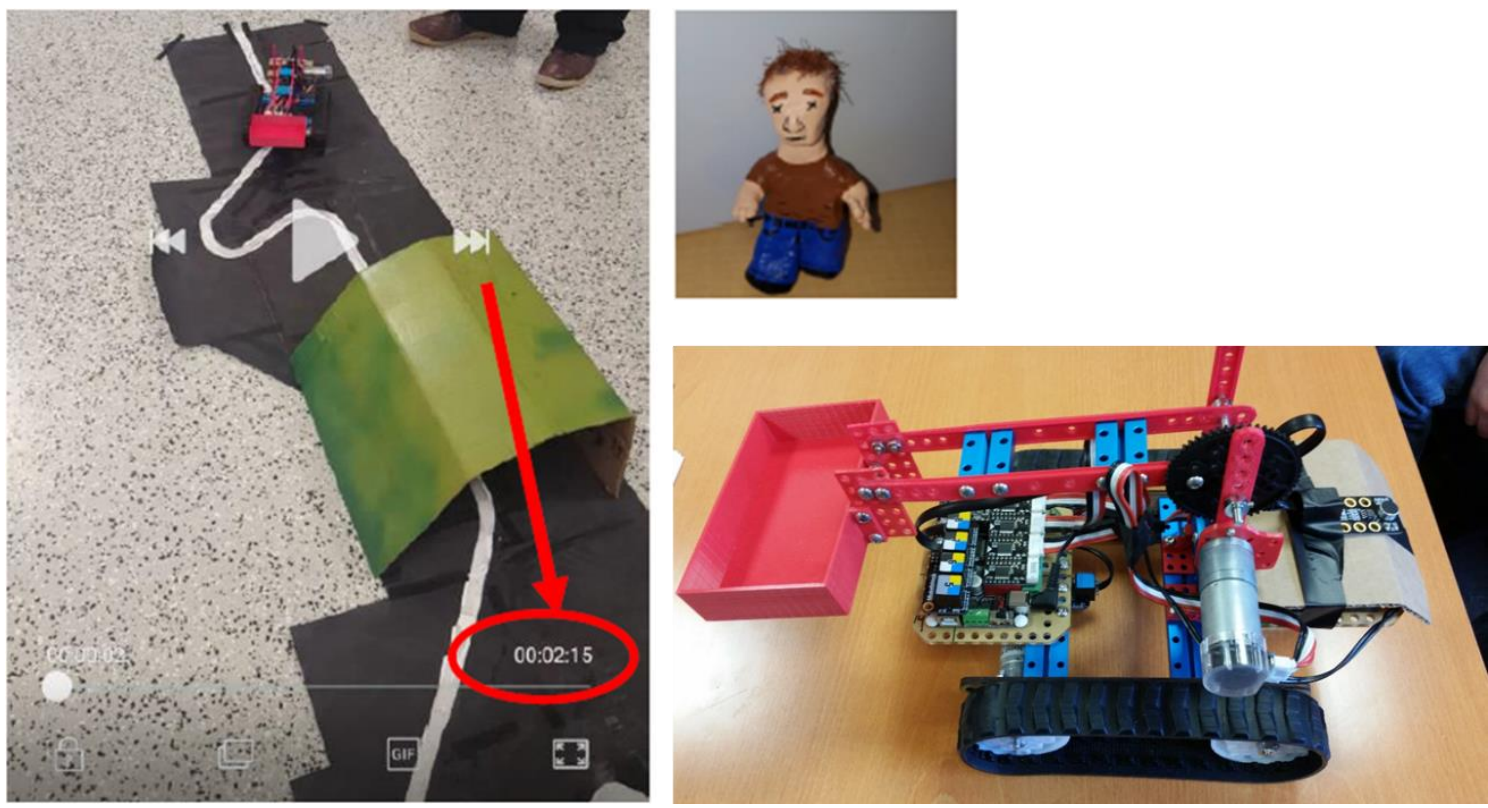

Figure 7. Robot exploring the theme of rejection from Frankenstein

As the robot followed the line shown on the left of Figure 7, it would pause at the turn in the road were the students had constructed a small village (not shown). Then the other students in the class, were instructed to yell at the robot. Once the yelling started the robot started up again and "hid" under the tunnel where it stayed until the students yelled at it again. At the end of the line the robot, which was carrying the "Frankenstein" model (above right) in the red basket, threw the Frankenstein model off the robot and onto the ground.

\section{Student Response Survey Results}

After the completion of the project the students were invited to participate in an anonymous survey concerning their experience with the project. Twenty-seven of sixty-one students 
participated in the survey. The primary contribution of this paper is in the observations of both the students and the faculty on the implementation and the outcomes of this project, especially in regards to student engagement. These will be presented as a combination of broad observations on the project, analysis of survey results, and specific feedback from students based on free response questions in the survey.

It was clear through the performance of the students throughout the project, that technical requirements were understood and achieved with at a high percentage, whereas the thematic aspect of the assignment was more difficult to grasp. Three major reasons may contribute to this. First, this type of assignment is very different from the typical assignments seen in technical classes and students may not feel as drawn to fully engage in humanities based assignments as in STEM based assignments. Second, students may not appreciate the overlapping nature of learning in various disciplines and settings, as well as the breadth of learning that is connected to the engineering profession. Finally, this type of assignment is also new to the faculty facilitating the project, and improvements in the implementation of the project would be beneficial.

\section{Student Engagement}

As seen in the sample reflections above, many responses were superficial and lacked depth. The lack of draw for some students to engage in the humanities based aspects of this assignment were seen in a variety of ways. Of the students that participated in the survey, only $11 \%$ reported to have read the entire book and $22 \%$ stated they read less than $20 \%$ of the book. Figure 8 shows that the majority of students did not fully interact with the book. 


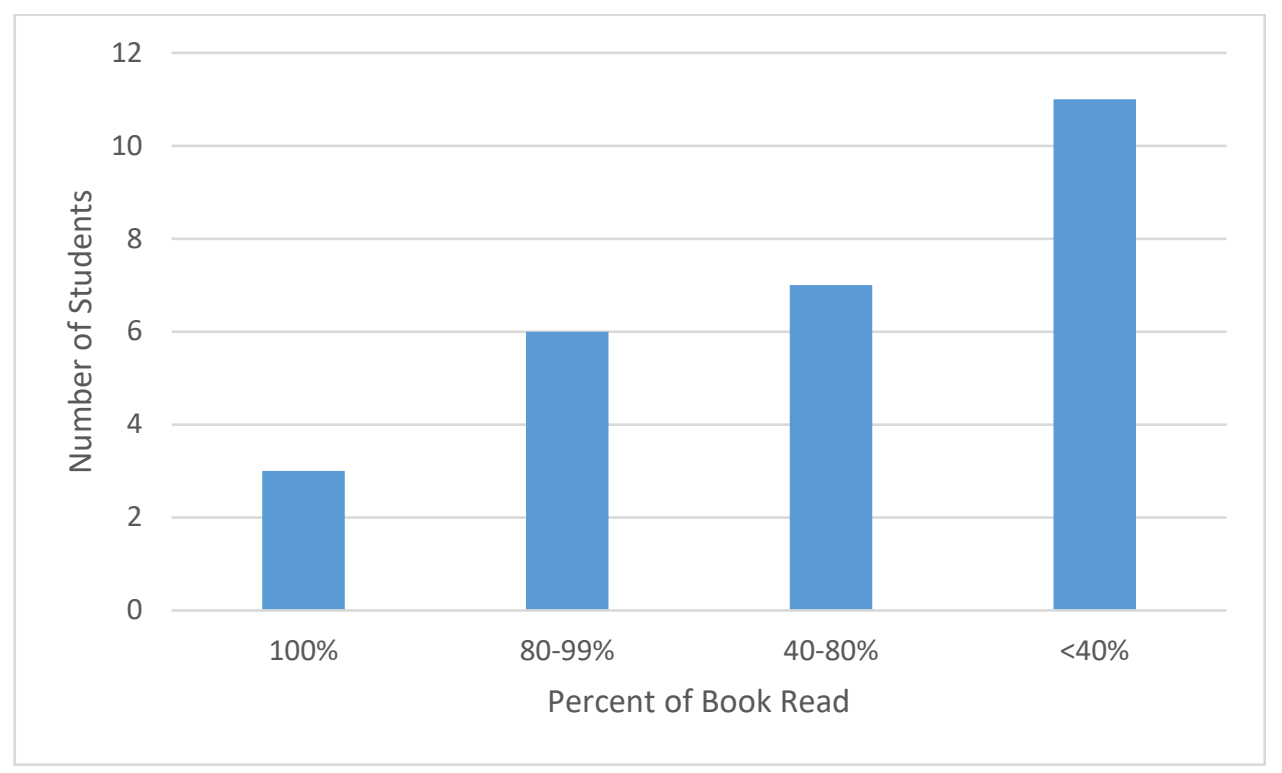

Figure 8 . Number of students who read varying amounts of the book

Even among those that read significant portions of the book, there did not seem to be an obvious correlation with enjoyment of reading. It is important to note that this is out of survey respondents, and potential overall reading percentages could be lower.

The topic of engagement with the text was also addressed in a variety of student comments in the free response questions of the survey.

Student Comment: "Many students do not like reading, because of this they did not fully encompass the full project. This hurt the students who did."

Student Comment: "Many engineering students do not like to read. Because of this the concepts the[y] generate from the book are most likely to be surface level."

Student Comment: "I know a lot of people that did not read the book."

Student Comment: "A disadvantage of using the book is that a lot of people didn't like the book. This probably jaded people's opinion of the project."

Student Comment: "I did not find the idea of reading to be exciting whatsoever." 
Although, only $15 \%$ of students said that incorporating reading the book expanded their understanding of engineering at all, 30\% reported it expanded their understanding of society, and $59 \%$ that it expanded their understanding of ethics. So, overall, the majority of students did see some benefit from interacting with the novel. One student reported:

Student Comment: "It required a lot more abstract thought and required us to think more creatively than we typically would."

\section{Interconnected Learning}

The findings reported above showing differences in perception of how reading the book expanded their understanding, seem to suggest barriers in the students minds between learning about different aspects of society. To say that your view of ethics is expanded, but not your understanding of society or of engineering seems disconnected. This disconnect in types of learning and understanding could be seen in other results as well.

Student Comment: "The main disadvantage was the time spent reading took away from other time learning."

Student Comment: "Taking time to read the book took time away that could have been used learning other things. It was difficult to make an actually useful robot design that related strongly to the book."

These comments suggest that students do not see reading literary works as a learning experience, or at least not an experience learning the things that are important or desired to them.

There was an attempt to help overcome these obstacles for the students by bringing a member of the humanities faculty into class to discuss the reflections and help relate these to the project. In particular the humanities faculty attempted to get the students to reflect on the lessons one could draw from Frankenstein within the context of making an autonomous robot. In regards to this, $45 \%$ of students said that this had no impact or negative impact on their engineering 
education, and $30 \%$ reporting no impact on their overall education. Conversely $23 \%$ said that this had moderate to high impact on their engineering education and $44 \%$ on their overall education. It is perhaps unsurprising that this single 50 minute interaction with a humanities professor did not provided the necessary impact to make this a truly useful exercise to the students. Moreover, while the humanities faculty did watch the final demonstrations they did not participate in the evaluation of the projects. Perhaps if the humanities faculty had participated in the evaluation, and the students were aware of this fact, the results on the final demonstrations would have been stronger.

\section{Discussion}

Overall, in spite of some negative results for the implementation of this project, still $63 \%$ of the students reported that they felt it was moderately to highly important to incorporate humanities into the sciences and engineering, with only $11 \%$ saying it was not important at all. In light of this it seems important to determine the approaches that would better facilitate this incorporation. Based on the results above, there are several suggestions for future implementation. Some of these are currently being addressed with following iterations of this project. Most notably, students did say reading Frankenstein helped with concept generation as the comments below illustrates.

Student Comment: "It gave the group ideas for the functions of the robot. Otherwise, it would have been harder to come up with something outside the ideas from the kit

Student Comment: "Advantages of using the book Frankenstein in the design process include being "forced" to connect the story to possible engineering problems and solutions. [I] say "forced" because [I] think that overall it was a good idea, but [I] know [I] wouldn't do it if left to my own devices. " 
One area of improvement for student engagement deals with the selection of source material.

This is in large part based on particular feedback from a student.

Student Comment: "I believe there are better books and or real world examples you could have used and [sic] instead of assigning a book to read over the span of a few weeks. $[\mathrm{M}]$ aybe post, different videos and articles every week of controversial topics in society. some examples would be one week look at the future of AI or even GMO's, the process of cloning. [T] his would allow the students to have many examples and more ideas. I believe that this would greatly improve [their] experience taking things in today society giving topics that may affect us sometime in our life. That would be better than a fiction book that only a few kids would enjoy reading. With multiple topics everyone is bound to have a slight interest in at least one topic."

There is a wide variety of works and platforms enveloped in the humanities. Finding topics, and avenues that engage the students is likely a valuable approach for exposing students to the connection between engineering and the humanities. One suggestion for this is to allow the students to first pick a topic that they are interested in, and then seek out sources on that topic that could aid in concept generation. Stipulations can be set on what sources would be acceptable to still get the breadth of coverage desired.

Another aspect that should be addressed in future projects is developing and facilitating understanding of the connection between various types of learning. For example, understanding that ethics is a part of engineering and society, and that developing understanding in one aspect can aid in the others. If students can see these connections, this could also enhance student engagement. This can in part be enhanced by incorporating the humanities faculty in the process. However, how to incorporate their help needs to be thoughtfully considered. One consideration was noted by a student:

Student Comment: "Having a[n] English professor come in and talk to the class about overall themes in the book was very helpful. It might be better to have the teacher come in earlier so the students have a better idea of what type of concepts they should be looking for." 
Finally, it was observed that generally, students are not naturally going to dig deeper in themes for abstract presentation in an engineering design setting, which makes it critical for the faculty to help walk them through this experience. Early, and repeated guidance on topic selection, and thought process is likely critical for success.

\section{Conclusions}

Overall, it seems that students can understand that there are lessons in the humanities that are relevant, but lack skills and/or motivation to relate them to their engineering field. This project attempted to allow the students to explore themes from the book Frankenstein, and to demonstrate those themes through an autonomous robot display. It was observed that the students largely lacked the engagement with the text necessary to develop deep thematic concepts. While some students were able to represent a given theme from the book in their reflection assignments, many remained superficial. This lack of engagement was seen in the results of the student survey as well. However, there was a majority of students that still thought it was important to incorporate the humanities with STEM. In light of this, it is suggested that future projects focus on allowing students to explore topics that seem relevant and interesting to themselves. It is believed that this would increase engagement and improve the depth of concepts generated. It is also important to bridge the gap between learning in various realms. For example, learning about ethics is in part learning about engineering. Finally, it is also critical for faculty to aid in this process. Faculty should be ready to help students to step back and see the bigger topics. In this way the vision of the students will be widened so that they can learn to learn more broadly. 


\section{References}

[1] D.L. Evans, B.W. McNeill and G.C. Beakley, "Design in Engineering Education: Past Views of Future Directions," Engineering Education, V80, N5, p. 517- 522, Jul-Aug 1990.

[2] Saterbak, A., \& Embree, M., \& Oden, M. "Client-based Projects in Freshman Design Paper," in Proceedings of the 2012 ASEE Annual Conference \& Exposition, San Antonio, TX, USA, June 2012, https://peer.asee.org/21074

[3] Pucha, R., \& Thurman, C. J., \& Yow, R., \& Meeds, C. R., \& Hirsch, J., "Engagement in Practice: Socio-technical Project-based Learning Model in a Freshman Engineering Design Course" in Proceedings of the 2018 ASEE Annual Conference \& Exposition, Salt Lake City, Utah, USA, June 2018. https://peer.asee.org/30390

[4] Dodson, K. H., \& Tipton, J. B., \& McDonald, M. P., \& Nordstrom, G., \& Gwinn, A. F., "Human-Centered Design Incorporated in the Freshman Year through an Active Learning Engineering Design Lab: Best Practices, Lessons Learned, and Proposed Improvements," in Proceedings of the 2018 ASEE Annual Conference \& Exposition, Salt Lake City, Utah, USA, June 2018.. https://peer.asee.org/30588

[5] Mueller, J., \& Aidoo, J., "Introducing Sustainable Design Principles in Freshman Civil Engineering Design" in Proceedings of the 2013 ASEE Annual Conference \& Exposition, Atlanta, Georgia, USA, June 2013. https://peer.asee.org/19837

[6] Esparragoza, I. E., "Incorporating Global and Ethical Issues in a Freshman Engineering Design Course through Collaborative Design Projects Paper" in Proceedings of the 2011 ASEE Annual Conference \& Exposition, Vancouver, BC, Canada, June 2011. https://peer.asee.org/18127

[7] Pruitt, L. A., "Introduction to Engineering Design for Freshman: Implementation of Leadership and Service Learning for Broadening Engineering Ingenuity," in Proceedings of the 2011 ASEE Annual Conference \& Exposition, Vancouver, BC, Canada, June 2011.. https://peer.asee.org/18185

[8] Chong, A., \& Wilkinson, L., \& Tihanyi, D., "Intersections of Humanities and Engineering: Experiments in Engineering Specific Humanities Electives and Pedagogies" in Proceedings of the 2014 ASEE Annual Conference \& Exposition, Indianapolis, Indiana, USA, June 2014. https://peer.asee.org/20694

[9] Wuerffel, E., \& Will, J. D., "Engineering in the Humanities: Interdisciplinary Projects in the Arts and Engineering," in Proceedings of the 2015 ASEE Annual Conference \& Exposition, Seattle, Washington, USA, June 2015. 10.18260/p.23968

[10] National Academies of Sciences, Engineering, and Medicine, The Integration of the Humanities and Arts with Sciences, Engineering, and Medicine in Higher Education: Branches from the Same Tree. Washington, DC: The National Academies Press, 2018. https://doi.org/10.17226/24988.

[11] Green Peace International, "NewBees," YouTube, 28-Apr-2014. [Online]. Available: https://www.youtube.com/watch?v=CGTNjPow3LM.

[12] Great Big Story, "These Kinetic Sculptures Hypnotize You,” YouTube, 28-Feb-2016. [Online]. Available: https://www.youtube.com/watch?v=PIbk4AKFMTc. 
[13] M. Shelley, Frankenstein, Annotated for Scientists, Engineers, and Creators of All Kinds. Kinds, E. Finn, D. H. Guston and J. Robert, Eds., The MIT Press, 2017. 